\title{
Copeptin for risk stratification in non- traumatic headache in the emergency setting: a prospective multicenter observational cohort study
}

Claudine Angela Blum ${ }^{1,3^{*}}$, Bettina Winzeler ${ }^{1}$, Nicole Nigro ${ }^{1}$, Philipp Schuetz ${ }^{3}$, Silke Biethahn ${ }^{2}$, Timo Kahles ${ }^{2}$, Cornelia Mueller ${ }^{1}$, Katharina Timper ${ }^{1,9}$, Katharina Haaf ${ }^{2}$, Janina Tepperberg ${ }^{2}$, Margareth Amort ${ }^{4}$, Andreas Huber ${ }^{5}$, Roland Bingisser ${ }^{6}$, Peter Stephan Sándor ${ }^{7}$, Krassen Nedeltchev², Beat Müller ${ }^{3}$, Mira Katan ${ }^{8 \dagger}$

and Mirjam Christ-Crain ${ }^{1+}$

\begin{abstract}
Background: In the emergency setting, non-traumatic headache is a benign symptom in $80 \%$ of cases, but serious underlying conditions need to be ruled out.

Copeptin improves risk stratification in several acute diseases. Herein, we investigated the value of copeptin to discriminate between serious secondary headache and benign headache forms in the emergency setting.

Methods: Patients presenting with acute non-traumatic headache were prospectively enrolled into an observational cohort study. Copeptin was measured upon presentation to the emergency department. Primary endpoint was serious secondary headache defined by a neurologic cause requiring immediate treatment of the underlying disease. Secondary endpoint was the combination of mortality and hospitalization within 3 months. Two board-certified neurologist blinded to copeptin levels verified the endpoints after a structured 3-month-telephone interview.

Results: Of the 391 patients included, 75 (19\%) had a serious secondary headache. Copeptin was associated with serious secondary headache (OR 2.03, 95\%Cl 1.52-2.70, $p<0.0001)$. Area under the curve (AUC) for copeptin to identify the primary endpoint was $0.70(0.63-0.76)$. After adjusting for age $>50$, focal-neurological abnormalities, and thunderclap onset of symptoms, copeptin remained an independent predictive factor for serious secondary headache (OR 1.74, 95\% Cl 1.26-2.39, $p=0.001)$. Moreover, copeptin improved the AUC of the multivariate logistic clinical model ( $p$-LR-test $<0.001$ ).

Even though copeptin values were higher in patients reaching the secondary endpoint, this association was not significant in multivariate logistic regression.
\end{abstract}

Conclusions: Copeptin was independently associated with serious secondary headache as compared to benign headaches forms. Copeptin may be a promising novel blood biomarker that should be further validated to rule out serious secondary headache in the emergency department.

Trial registration: Study Registration on 08/02/2010 as NCT01174901 at clinicaltrials.gov.

Keywords: Headache, Head pain, Emergency, Biomarker, Copeptin, Vasopressin

\footnotetext{
* Correspondence: claudineblum@yahoo.com; claudine.blum@ksa.ch

${ }^{\dagger}$ Equal contributors

'Division of Endocrinology, Department of Internal Medicine, University

Hospital Basel, Basel, Switzerland

${ }^{3}$ Internal Medicine, Medical University Clinic, Kantonsspital Aarau, Tellstrasse,

CH-5001 Aarau, Switzerland

Full list of author information is available at the end of the article
} 


\section{Background}

Headache has a high prevalence in the general population and presents an important public health problem [1].

Non-traumatic headache has a prevalence of 0.5 to $4.5 \%$ in patients presenting to the emergency department (ED), and it remains a major diagnostic challenge [2-5]. The majority of these patients have benign headache. However, in $3.8-20 \%$ of headache patients, a headache secondary to a potentially life-threatening condition is diagnosed with immediate implications for therapeutic interventions. These include subarachnoidal hemorrhage, cerebral aneurysm, intracranial bleeding, sinus vein thrombosis, temporal arteriitis, or meningitis [2, 5-7]. It has been shown by various authors that red flags like age $>50$ years, focal-neurological signs, thunderclap onset of symptoms or altered mental status have a remarkable negative predictive value around 0.98-0.99, however with varying sensitivities (between 0.39 and 100\%) and specificities (between 65 and 98\%) [7-11]. To improve the differentiation of benign headaches from secondary, potentially serious headache forms, various clinical algorithms which include these red flags have been proposed, but they are only inconsistently applied in clinical practice $[7,12]$. Therefore, the use of biomarkers has potential merits as diagnostic tools.

Only few biomarkers have been investigated in headache, [13-22] and except D-dimer in specific vascular etiologies, $[14,17]$ they have not found their way into emergency algorithms. To our knowledge, there is no data on biomarkers for discriminating between serious secondary and benign headache forms.

Copeptin is a hypothalamic stress hormone that mirrors the individual stress level even more subtly than circulating cortisol [23]. In its function as a stress hormone, copeptin serves as a prognostic marker in various acute disease states, such as cerebrovascular event, myocardial infarction or pneumonia [24]. Apparently, copeptin allows tapping an endogenous information system of our body that, through mechanisms still poorly understood, assesses the severity of damage [25].

We herein prospectively evaluated the use of copeptin for discriminating between benign headache forms and serious secondary headache, and the degree of association with serious secondary headache.

\section{Methods}

\section{Study design and participants}

This multicenter observational study was performed at the ED of two tertiary care hospitals in northern Switzerland from October 2010 to March 2013.

All patients with current non-traumatic headache as a chief complaint presenting to the ED or as an emergency to the medical or neurological walk-in clinic of the two tertiary centers were eligible and screened.
Exclusion criteria were trauma within 7 days, chronic headache defined as $>3$ months duration, age $<18$ years, missing informed consent, and inability to comply with study procedures due to insufficient knowledge of the German language.

Chronic headache with an acute exacerbation was not an exclusion criterion.

\section{Clinical variables}

Recruitment was during $24 \mathrm{~h}$ and on weekdays and weekends.

After informed consent was given by the patient, baseline data were assessed by questionnaire at the time of the acute presentation. This included medical history, age, gender, body mass index, ethnicity and country of origin, past medical history, smoking history, current medication, alcohol and coffee consumption (units per day), and substance abuse. Clinical headache presentation and headache history was assessed by detailed standardized, validated questionnaire containing the International Classification of Headache Disorders (ICHD) [26] and included depression screening by Primary Care Evaluation of Mental Disorders (PRIME-MD) questionnaire [27] and categorization by a validated, diagnostic algorithm into one of four clinical scenarios (Thunderclap headache, meningitis, new or worsening headache, headache similar to previous episodes) as described by Grimaldi et al. [7]. Disease severity, quality of daily living, and interference of symptoms with quality of life was assessed using the standardized, validated migraine disability assessment (MIDAS) [28].

Clinical items assessed by the treating physician were recorded at the time of the acute presentation and included physical examination, neurological assessment, Glasgow Coma Scale, blood pressure, pulse rate, and body temperature.

\section{Blood sampling and assays}

Blood samples for copeptin measurement were drawn on admission in the emergency department and were either obtained from an indwelling venous catheter or by venous puncture. Blood samples were immediately centrifuged and stored in the refrigerator. Apart from blood sampling for study purposes, routine blood sampling was performed at the discretion of the treating physicians and was performed in 354 (91\%) patients.

At ED discharge, the diagnostic work-up was recorded, including neuroimaging, lumbar puncture and additional disease-specific evaluations in secondary headaches.

Blood Plasma was frozen at $-70{ }^{\circ} \mathrm{C}$. Copeptin levels were measured by batch analysis with a commercial chemiluminescence sandwich immunoassay (B.R.A.H.M.S LUMItest CT-proAVP, B.R.A.H.M.S AG, Hennigsdorf/ Berlin, Germany), as described in detail elsewhere, with a 
lower detection limit of the assay of $0.4 \mathrm{pmol} / \mathrm{L}$ and the functional assay sensitivity $(<20 \%$ interassay $\mathrm{CV})$ of $<1$ $\mathrm{pmol} / \mathrm{L})[29,30]$. The treating physicians and the study team were blinded to copeptin levels at all times.

\section{Follow-up}

At 3 months, a structured follow-up telephone interview was performed to assess course and outcome of the disease. The earliest possible contact was 14 days before this time point. If the patient was not reached until 4 weeks after the scheduled interview, his primary care physician was contacted for follow-up information. If the patient had consulted the hospital since study inclusion and no other data was available, this date was taken as time of last follow-up. To minimize loss of follow-up, the study team tried to re-contact the patient until the last scheduled follow-up interview in June 2013. The final headache diagnosis and the judgement whether the headache had been serious or not was made in each patient after the follow-up interview by two independent physicians by chart review and verified by a boardcertified neurologist. Disagreements between study physicians were resolved by a final adjudication of an independent neurologist. They were all blinded to copeptin levels.

\section{Outcomes}

The objective of this study was to evaluate copeptin as a marker for risk stratification in non-traumatic headache, namely for ruling out serious secondary causes of headache. The primary endpoint was serious secondary headache as opposed to benign headache.

Our hypothesis was that based on previous studies on copeptin in other diseases, $[29,31-34]$ a cutoff of $\leq 5$ $\mathrm{pmol} / \mathrm{l}$ would have a sensitivity of $\geq 97 \%$ for ruling out serious secondary headache causes, and that a cutoff of $\geq 20 \mathrm{pmol} / \mathrm{l}$ would have a specificity of $\geq 90 \%$ for the presence of serious secondary NTH.

The secondary endpoint was the combined endpoint of death or hospitalization of any cause within 3 months.

Headache was defined according to the International Headache Society as pain located above the orbitomeatal line. A serious secondary headache was defined as a headache with a neurologic cause as listed in the ICHDII criteria [9] requiring subsequent treatment of the underlying disease or condition, which, if left untreated, would have the potential risk of permanent damage or death(see also Appendix). All other patients with an uneventful 3-month follow-up were diagnosed with benign headache.

Our gold standard for the final diagnosis of headache was the clinical diagnosis according to ICHD-II criteria after 3 months, verified by a board-certified neurologist. Headaches which clearly belonged to the primary headache entities but did not fulfill the full diagnostic criteria were classified as "primary headache, not classified", e.g. a first episode of migraine, which did not yet fulfill the criterion of at least 3 episodes.

As this study was started before the current version ICHD3-beta was in place, we continued to use the ICHD-II classification for consistency throughout the whole study.

\section{Analysis}

Discrete variables are summarized as counts (percentage), and continuous variables as medians and interquartile ranges(IQRs). Frequency comparison was done by chi-square test. Two-group comparisons of continuous variables were performed using Student's $t$-test or the Mann-Whitney-U test, depending on their distribution. Receiver operating characteristic (ROC) curve for copeptin was calculated, and the area under the ROC curve (AUC) was used to assess the discriminatory potential of copeptin to accurately identify patients with serious secondary headache [35]. Further, we calculated logistic regression models to estimate the magnitude of the association between copeptin and the pre-specified endpoints. To assess the independence of this association from other risk scores and important outcome predictors (chosen from the published literature) we calculated multivariable regression models and added all parameters based on their association in the univariate models (p-value cut off for further evaluation was $<0.05$ ). This included age $>50$ years, sudden onset of headache, an abnormal neurological examination, [11] clinical scenario 4 (history of previous similar headache) for the clinical model (multivariate model 1), [7] D-dimer, fibrinogen, leukocytes and C-reactive protein $[13,36]$ for the laboratory model (multivariate model 2). To avoid overfitting, we calculated two final models, thus no more than one variable per ten events were included in these final two models. In addition, we compared the ROC curves based on the logistic models with and without copeptin using the likelihood ratio test [37]. All statistical tests were 2-tailed. $p<0.05$ was considered significant. STATA 12.1 (StataCorp LP, College Station, TX, USA) was used for data analysis.

\section{Sample size considerations}

Based on the patient numbers from previous years, about 400 patients per year were estimated to be eligible for this study. With an estimated informed consent rate of $90-95 \%$ and an estimated loss of follow-up of 5-10\%, 360 patients were estimated to complete the study. According to pre-existing literature, $10-20 \%$ of these 360 patients would present with serious non-traumatic headache, thus 50-60 patients would reach the primary endpoint. Based on the literature and pilot data [25], a mean 
copeptin difference of $15 \mathrm{pmol} / \mathrm{L}$ (SD of $30 \mathrm{pmol} / \mathrm{L}$ ) between these groups was expected. This difference would be detected with a power of $80 \%$.

\section{Results}

\section{Characteristics of study subjects}

From October 2010 to March 2013, 398 patients were enrolled into the CoHead-Study (see Fig. 1 for study flow chart). The 3-month telephone interviews were terminated in July 2013. 7 patients were lost to follow-up and were therefore not included in the analysis.

Baseline characteristics are shown in Table 1. Median age was 41 (IQR 30-57), 146 patients (37\%) were men. Median headache duration was 3 days (IQR 0.5-7); median pain strength on Visual Analogue Scale (VAS) was 8 (IQR 6-9). At discharge, a primary headache form was diagnosed in 219 (56\%) patients, and secondary headache in 172 (44\%) patients, of which 75 (19.2\%) were classified as serious.

The group of serious secondary headache was heterogeneous: 8 patients (2\%) had subarachnoidal hemorrhage, 7 (1.8\%) sinus vein thrombosis, $10(2.6 \%)$

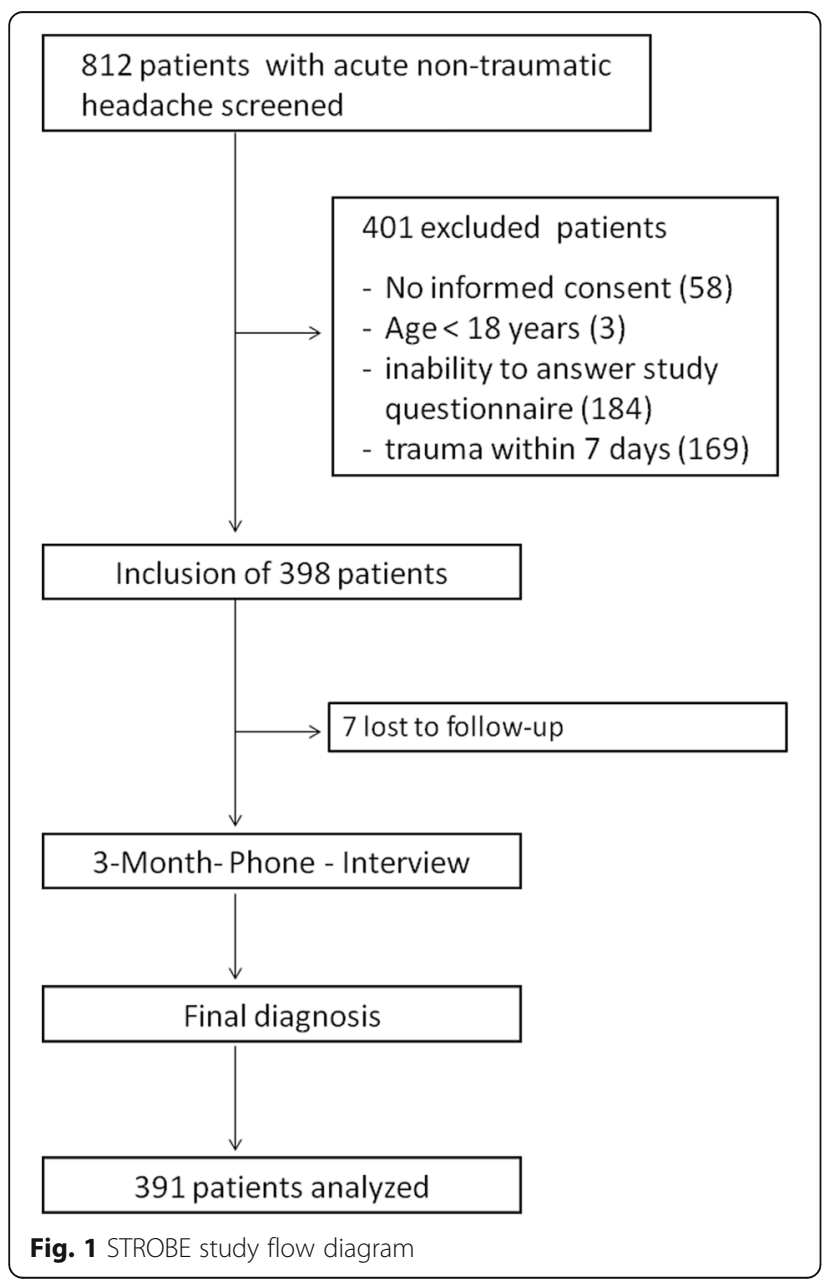

intracranial bleeding, and 7 (1.8\%) had viral meningitis (detailed diagnoses are shown in Table 2).

Median time to follow-up was 99 days (IQR 91-118; range 9-632). Two patients (0.5\%) died during followup. Both had initially presented with serious secondary headache: one with subarachnoidal bleeding and one with bacterial meningitis. Hospitalization rate was 94 patients $(24.0 \%)$, of which 61 (15.6\%) were hospitalized immediately following study inclusion.

\section{Main results}

Association of copeptin with serious secondary headache Copeptin levels were higher in serious secondary headache forms as compared to all other headache forms (median $6.44 \mathrm{pmol} / \mathrm{L}$ (IQR 3.97-11.29) vs. $3.89 \mathrm{pmol} / \mathrm{L}$ (IQR 2.59$6.10)(p<0.0001)$, see Fig. 2). The AUC for copeptin to detect serious secondary headache was 0.70 (95\% confidence interval (CI) 0.63-0.76). At the predefined rule-out cutoff for serious secondary headache of $5.0 \mathrm{pmol} / \mathrm{L}$, copeptin had a sensitivity of $64.4 \%$; at the predefined rule-in cutoff of 20 $\mathrm{pmol} / \mathrm{L}$, copeptin had a specificity of $95.3 \%$ to rule in a serious secondary headache. At the cutoff of $2.5 \mathrm{pmol} / \mathrm{L}$, copeptin had a sensitivity of $91.8 \%$ to rule out serious secondary headache, i.e. a negative predictive value of 0.93 . For different copeptin cutoffs, see Table 3.

In univariate analysis, copeptin was associated with serious secondary headache with an OR of 2.03 (95\%CI $1.52-$ $2.70, p<0.0001)$. Other strong predictors were age $>50$ years (OR 2.83, 95\%CI 1.69-4.74, $p<0.0001$ ), an abnormal neurological exam (OR 3.50, 95\%CI 1.99-6.14, $p<0.0001$ ), and thunderclap onset of symptoms (OR 4.23, 95\%CI 2.38 7.52, $p<0.0001$; for detailed results of the univariate analysis, see Table $4 a$ ).

We included the strongest clinical risk factors from the univariate analysis along with copeptin in a multivariate model. After adjustment, copeptin remained independently associated with serious secondary headache (OR 1.74, 95\%CI 1.26-2.39, $p=0.001)$. The clinical factors age $>50$ years (OR 2.25, 95\%CI 1.28-3.96), male gender (OR 1.84, 95\%CI 1.27-3.52), focalneurological findings (OR 2.63, 95\%CI 1.99-6.14), and thunderclap onset (OR 2.89, 95\%CI 2.38-7.52) also remained associated with serious secondary headache (for detailed values, see Table $4 \mathrm{~b}$ ).

Moreover, copeptin improved the AUC of the multivariate logistic clinical model (model without copeptin: AUC 0.735 (95\%CI 0.664-0.807), model with copeptin: AUC 0.7544 (95\% CI0.683-0.825), pLR-test < 0.001).

In a second multivariate model, laboratory values including fibrinogen, leukocytes and copeptin were assessed. Only copeptin remained associated with serious secondary headache (OR 1.80, 95\% CI 1.33-2.44, $p<0.0001$; for detailed values, see Table 4c). 
Table 1 Baseline characteristics ${ }^{\mathrm{a}}$

\begin{tabular}{|c|c|c|c|}
\hline Baseline characteristics & $\begin{array}{l}\text { All patients } \\
(n=391)\end{array}$ & $\begin{array}{l}\text { Benign headache } \\
(n=316)\end{array}$ & $\begin{array}{l}\text { Serious secondary headache } \\
(n=75)\end{array}$ \\
\hline Age (years) & $41(30-57)$ & $39(28-54)$ & $56(40-66)$ \\
\hline Male sex & $146(37.3 \%)$ & $107(33.9 \%)$ & $39(52.0 \%)$ \\
\hline \multicolumn{4}{|l|}{ Comorbidities } \\
\hline Hypertension & $51(13.0 \%)$ & $36(11.4 \%)$ & $15(20.0 \%)$ \\
\hline Coronary heart disease & $17(4.3 \%)$ & $8(2.5 \%)$ & $9(12.0 \%)$ \\
\hline Atrial fibrillation & $2(0.5 \%)$ & $1(0.3 \%)$ & $1(1.3 \%)$ \\
\hline Cerebrovascular ischemic disease & $2(0.5 \%)$ & 0 & $2(2.7 \%)$ \\
\hline Chronic obstructive lung disease & $1(0.3 \%)$ & $1(0.3 \%)$ & 0 \\
\hline Multiple sclerosis & $2(0.5 \%)$ & $2(0.6 \%)$ & 0 \\
\hline Chronic pain syndrome & $7(1.8 \%)$ & $6(1.9 \%)$ & $1(1.3 \%)$ \\
\hline Depression & $17(4.3 \%)$ & $16(5.1 \%)$ & $1(1.3 \%)$ \\
\hline Epilepsy & $9(2.3 \%)$ & $3(0.9 \%)$ & $6(8.0 \%)$ \\
\hline \multicolumn{4}{|l|}{ Associated headache symptoms } \\
\hline Nausea & $214(54.7 \%)$ & $178(56.3 \%)$ & $36(48.0 \%)$ \\
\hline Vomiting & $106(27.1 \%)$ & $83(26.3 \%)$ & $23(30.7 \%)$ \\
\hline Visual aura & $124(31.7 \%)$ & 107 (33.9\%) & $17(22.7 \%)$ \\
\hline Photophobia & $190(48.6 \%)$ & $160(50.6 \%)$ & $30(40.0 \%)$ \\
\hline Thunderclap onset headache & $67(17.1 \%)$ & $39(12.3 \%)$ & $28(37.3 \%)$ \\
\hline Nuchal rigidity & $10(2.6 \%)$ & $6(1.9 \%)$ & $4(5.3 \%)$ \\
\hline \multicolumn{4}{|l|}{ Scenario $^{b}$} \\
\hline 1: Worst headache ever & $67(17.1 \%)$ & $39(12.3 \%)$ & $28(37.3 \%)$ \\
\hline 2: fever/neck stiffness & $26(6.6 \%)$ & $21(6.6 \%)$ & $5(6.7 \%)$ \\
\hline 3: recent worsening & $169(43.2 \%)$ & $141(44.6 \%)$ & $28(37.3 \%)$ \\
\hline 4: history of previous similar headache & $112(28.6 \%)$ & $99(31.3 \%)$ & $13(17.3 \%)$ \\
\hline 5: none of the above & $17(4.3 \%)$ & $16(5.1 \%)$ & $1(1.3 \%)$ \\
\hline \multicolumn{4}{|l|}{ Clinical findings } \\
\hline Systolic blood pressure (mmHg) & $134(121-148)$ & $131(120-145)$ & $139(125-159)$ \\
\hline Diastolic blood pressure (mmHg) & $80(71-88)$ & $80(70-87)$ & $78(73-89)$ \\
\hline Temperature $\left({ }^{\circ} \mathrm{C}\right)$ & $37(36.7-37.4)$ & $37.0(36.7-37.4)$ & $37.1(36.7-37.4)$ \\
\hline Headache duration (days) & $3(0.5-7)$ & $2(1-7)$ & $3(1-6)$ \\
\hline Visual Analogue Scale (0-10) for pain at ED & $8(6-9)$ & $8(6-9)$ & $8(5-10)$ \\
\hline Focal-neurological finding & $74(18.9 \%)$ & $46(14.6 \%)$ & $28(37.3 \%)$ \\
\hline Immediate hospitalization & $61(15.6 \%)$ & $39(12.3 \%)$ & $22(29.3 \%)$ \\
\hline
\end{tabular}

data are shown as median (IQR) or $\mathrm{n}(\%)$

${ }^{b}$ clinical scenarios according to Grimaldi et al. [7]

Scenario 1 (worst headache ever): thunderclap-onset headache suggestive for subarachnoidal bleeding

Scenario 2 (fever/neck stiffness): potential meningitis

Scenario 3 (recent worsening) corresponds to tumor or temporal arteriitis

Scenario 4 (history of previous similar headache) corresponds to a primary headache form

Association of copeptin with mortality or hospitalization In the $94(24.0 \%)$ patients reaching the composite endpoint death or hospitalization of any cause within 3 months, copeptin values were higher as compared to patients without these events (median $6.44 \mathrm{pmol} / \mathrm{L}(\mathrm{IQR}$ $3.97-11.29$ ) vs. 3.89 (IQR 2.59-6.01; $p=0.0006$ ). The AUC for the composite endpoint was 0.62 (95\%CI 0.56 -
0.68). In univariate logistic regression analysis, copeptin was a predictor for the composite endpoint (OR 1.45, 95\%CI 1.12-1.88, $p=0.005$ ).

Other strong predictors were age $>50$ years (OR 2.77, 95\%CI 1.72-4.46), an abnormal neurologic exam (OR $4.23,95 \% \mathrm{CI} 2.47-7.24)$, thunderclap onset of headache (OR 3.04, 95\%CI 1.75-5.29), clinical scenario 4 (history 
Table 2 Headache classification

\begin{tabular}{ll}
\hline Headache classification $(n=391)$ & $n(\%)$ \\
\hline Primary headache & $219(56.0)$ \\
- Primary headache, not classified & $38(9.7)$ \\
- Migraine & $114(29.1)$ \\
- Tension-type headache & $51(13.0)$ \\
- Cluster headache & $4(1.0)$ \\
- Trigeminus neuralgia & $6(1.5)$ \\
- Medication overuse headache & $6(1.5)$ \\
Secondary headache & $172(44.0)$ \\
- Not serious & $97(24.8)$ \\
- Serious: & $75(19.2)$ \\
- Subarachnoidal bleeding & $8(2.0)$ \\
- Sinus vein thrombosis & $7(1.8)$ \\
- Intracerebral bleeding & $10(2.6)$ \\
- Cerebral tumor & $6(1.5)$ \\
- Cerebral ischemia & $6(1.5)$ \\
- Dissection of carotid artery & $4(1.0)$ \\
- Temporal arteriitis & $3(0.8)$ \\
- Bacterial meningitis & $1(0.3)$ \\
- Viral meningoencephalitis & $7(1.8)$ \\
- Neuroinflammatory disease & $4(1.0)$ \\
- Chronic subdural hematoma & $5(1.3)$ \\
- High intracranial pressure & $3(0.8)$ \\
- Low intracranial pressure & $3(0.8)$ \\
- Hypertensive urgency & $1(0.3)$ \\
- Associated with epileptic seizure & $5(1.3)$ \\
- Herpes zoster with cranial nerve affection & $1(0.3)$ \\
- Acute glaucoma & $1(0.3)$ \\
\hline 31 systemic infecions, 2 en
\end{tabular}

${ }^{a} 31$ systemic infections, 2 electrolyte disorders, 23 headaches due to teeth, facial skin or otorhinolaryngologic aetiology, 6 cases of arterial hypertension, 5 muscular headaches, 4 psychosomatic causes, 1 medication side effect, 1 multifactorial headache. 4 residual post-traumatic headaches, 8 hypoliquorrhea syndromes where no measures were necessary, 1 residual postoperative headache, 7 mild viral meningitis without detection of any pathogen, 1 pseudotumor cerebri without necessity of intervention, 1 patient each with headache secondary to Bell's palsy, Tolosa Hunt syndrome, and polyneuritis cranialis

${ }^{\mathrm{b}}$ Neuritis vestibularis, Miller-Fisher syndrome, clinically isolated syndrome, and retrobulbar neuritis

of previous similar headache; OR 0.56 , 95\%CI $0.32-$ 0.97), and C-reactive protein (OR 1.31, 95\%CI 1.07-1.60; see also Table 4a). After inclusion of the significant clinical predictors from the univariate analysis along with copeptin in a multivariate model, only age $>50$ (OR 2.34 , 95\% CI 1.41-3.89), focal-neurological findings (OR 3.41, 95\% CI 1.94-6.02) and thunderclap onset (OR 2.21, 95\% CI 1.18-4.15) remained associated with the composite endpoint death or hospitalization, but not copeptin (for detailed values, see Table $4 \mathrm{~b}$ ). In the second multivariate model, C-reactive protein (OR 1.27, 95\%CI 1.04-1.56) but not copeptin (OR 1.39 (95\%CI 1.0-1.94), $p=0.05$ ), remained associated with death or hospitalization, (For detailed values, see Table 4c).

\section{Limitations \\ We are aware of potential limitations.}

First, we included patients with headache irrespective of the underlying cause or disease. This leads to an inhomogeneous case mix with small numbers of each underlying cause, both in benign and in serious secondary headaches. However, using broad inclusion criteria reduces selection bias and, arguably, represents the true clinical population admitted to an emergency setting with acute headache.

Second, our gold standard for the final diagnosis of headache was the clinical diagnosis according to ICHD criteria after 3 months, verified by a board-certified neurologist. We abstained from brain imaging due to organizational and monetary restraints. In patients without brain imaging, there remains a small risk that a cerebral pathology may have been missed. However, we considered it to be rather unlikely that a clinically relevant cerebral pathology would remain unnoticed at 3 months. Moreover this would have introduced a bias towards the null hypothesis thus underestimating the real association.

Third, even though we aimed to recruit $24 \mathrm{~h}$ per day and 7 days per week, sampling error is possible, as patients arriving at night might have been missed by the staff on duty. Furthermore, this cohort represents an emergency department population and not the general headache patient.

Fourth, as copeptin rises after a stress stimulus independent from its cause, potential confounding factors have to be ruled out, such as hypoxia or hypovolemia, and inflammatory states [38-40].

\section{Discussion}

Our main finding is that copeptin was higher in serious secondary headaches requiring subsequent treatment of the underlying disease, as compared to benign headache forms. Importantly, after adjusting for the classical clinical risk factors age $>50$, sudden onset of headache and abnormal neurological exam [11], copeptin remained an independent risk factor for serious secondary headache. However, the initial hypothesis that copeptin would rule out serious secondary headache at the predefined cutoff of $5.0 \mathrm{pmol} / \mathrm{L}$ and rule in serious secondary headache at $20 \mathrm{pmol} / \mathrm{L}$ with a high sensitivity and specificity could "as is" not be confirmed. But at a lower cutoff level of $2.5 \mathrm{pmol} / \mathrm{L}$, copeptin had a sensitivity of $>90 \%$.

The most commonly postulated mechanism for the early copeptin elevation in acute illness is that copeptin reflects the activation of the hypothalamus-pituitaryadrenal axis at the hypothalamic level [41]. Copeptin 


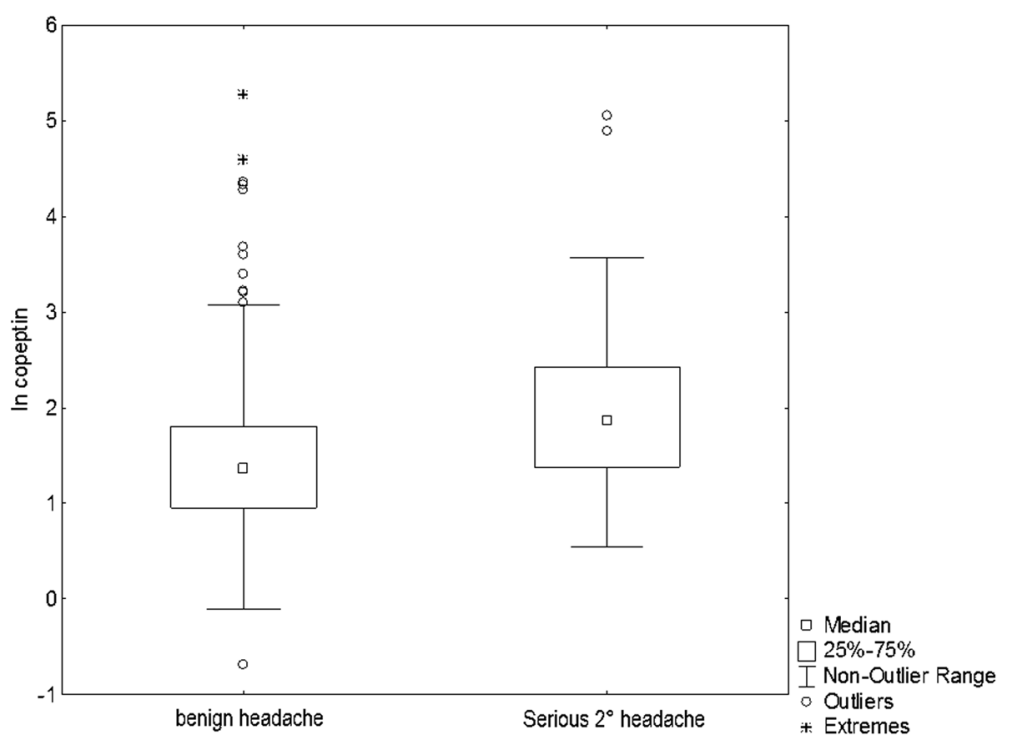

Fig. 2 Boxplot of copeptin values

promptly rises in different physical stress situations, correlating with the magnitude of stress [41-43]. Consequently, copeptin has been shown to be useful for an early rule out of acute myocardial infarction [29] and for prognosis in acute ischemic stroke [31]. We now show that copeptin may also be a promising marker for ruling out serious secondary headaches.

In acute headache with its high burden of disease [44], no biomarker has been established in clinical routine to improve discrimination between serious secondary and benign headache forms, even though fast and early identification of serious secondary headaches at the ED is crucial and has remained an unmet clinical need [2]. Algorithms based on clinical features do exist, but are inconsistently applied; [2] thus, there is room for improvement. Some biomarkers have been explored when specific causes of secondary headache were suspected, such as D-dimers for ruling-out sinus vein thrombosis [14]. Furthermore, there have been efforts for biomarker-guided treatment in migraine, for example by predicting treatment response to triptans by measuring levels of calcitonin gene-related peptide or neurokinin A [22]. Based on our data, copeptin seems to have

Table 3 Sensitivity and Specificity of copeptin to predict serious secondary headache at different cutoffs

\begin{tabular}{lcc}
\hline Copeptin value & Sensitivity (\%) & Specificity (\%) \\
\hline $2.5 \mathrm{pmol} / \mathrm{l}$ & 91.8 & 23.3 \\
$5.0 \mathrm{pmol} / \mathrm{l}$ & 64.4 & 66.7 \\
$10.0 \mathrm{pmol} / \mathrm{l}$ & 27.4 & 89.9 \\
$20.0 \mathrm{pmol} / \mathrm{l}$ & 12.3 & 95.3 \\
$30.0 \mathrm{pmol} / /$ & 5.5 & 96.5 \\
\hline
\end{tabular}

potential as a biomarker in unselected patients presenting with acute non-traumatic headache to the emergency department.

However, as copeptin rises after stress independent from its cause, potential confounding factors have to be ruled out, especially extra-neurologic causes such as systemic inflammation. Further studies seem warranted which analyze the influence of stress and pain itself on copeptin values before copeptin may be introduced into clinical decision-making.

Interestingly, male gender was independently associated with serious secondary headache in multivariate analysis. We attribute this finding to the fact that primary headache, especially migraine, is more frequent in women [45].

Even though copeptin has been shown to predict adverse outcome in various diseases [46, 47], there was only a trend for the association with the combined endpoint of death or hospitalization in this study after adjusting for all other relevant risk factors. Copeptin was not associated with mortality or hospitalization in multivariate analysis. When looking only at mortality, copeptin levels were higher in nonsurvivors as compared to survivors. However, due to the very small number of nonsurvivors $(n=2)$, this finding needs further evaluation in larger cohorts.

Copeptin seems therefore not to be an ideal marker to identify patients in need for hospitalization, probably because there are other factors contributing to hospitalization which are not sufficiently reflected by copeptin levels, such as psychosocial factors (e.g., need for nursing care, patients' fears of worsening or uncontrollable pain), comorbidities, or organizational reasons (observation until further investigations were performed, i.e. at night and on week-ends). 
Table 4 Main results: univariate and multivariate analysis of primary and secondary endpoint*

\begin{tabular}{|c|c|c|c|c|c|c|}
\hline \multicolumn{7}{|c|}{ a. Univariate analysis of primary and secondary endpoint } \\
\hline \multirow[b]{2}{*}{ Predictors } & \multicolumn{3}{|c|}{ Serious secondary headache } & \multicolumn{3}{|c|}{ Composite endpoint mortality or hospitalization } \\
\hline & OR & $95 \% \mathrm{Cl}$ & $p$ & OR & $95 \% \mathrm{Cl}$ & $p$ \\
\hline Copeptin $\left(\ln ^{a}\right)$ & 2.03 & $1.52-2.70$ & $<0.0001$ & 1.45 & 1.12.1.88 & 0.005 \\
\hline Age $>50$ & 2.83 & $1.69-4.74$ & $<0.0001$ & 2.77 & $1.72-4.46$ & $<0.0001$ \\
\hline Male gender & 2.12 & $1.27-3.52$ & 0.004 & 1.41 & $0.88-2.27$ & 0.150 \\
\hline Focal-neurological symptoms & 3.50 & $1.99-6.14$ & $<0.0001$ & 4.23 & $2.47-7.24$ & $<0.0001$ \\
\hline Thunderclap onset & 4.23 & $2.38-7.52$ & $<0.0001$ & 3.04 & $1.75-5.29$ & $<0.0001$ \\
\hline Scenario $4^{*}$ & 0.46 & $0.24-0.87$ & 0.018 & 0.56 & $0.32-0.97$ & 0.040 \\
\hline D-Dimer $\left(\ln ^{\mathrm{a}}\right)$ & 1.50 & $1.00-2.27$ & 0.052 & 1.28 & $0.87-1.89$ & 0.205 \\
\hline Fibrinogen $\left(\ln ^{\mathrm{a}}\right)$ & 2.95 & $1.10-7.89$ & 0.031 & 2.29 & $0.91-5.80$ & 0.080 \\
\hline C-reactive protein $\left(\ln ^{\mathrm{a}}\right)$ & 1.06 & $0.87-1.30$ & 0.544 & 1.31 & $1.07-1.60$ & 0.010 \\
\hline Leukocyte count ( $\left(n^{a}\right)$ & 2.04 & $1.01-4.13$ & 0.046 & 0.63 & $0.34-1.16$ & 0.136 \\
\hline
\end{tabular}

b. Multivariate model 1: Copeptin and clinical variables

Serious secondary headache

$\begin{array}{llll}\text { Predictors } & \text { OR } & 95 \% \mathrm{Cl} & \text { Predictors } \\ \text { Copeptin }\left(\mathrm{In}^{\mathrm{a}}\right) & 1.73 & 1.26-2.40 & 0.001 \\ \text { Age }>50 & 2.25 & 1.28-3.96 & 0.005 \\ \text { Male gender } & 1.84 & 1.04-3.26 & 0.035 \\ \text { Focal-neurological symptoms } & 2.63 & 1.40-4.92 & 0.003 \\ \text { Thunderclap onset }_{\text {Scenario 4 }}^{\mathrm{b}} & 2.90 & 1.49-5.65 & 0.002 \\ & 0.73 & 0.35-1.50 & 0.388\end{array}$

Composite endpoint mortality or hospitalization

$\begin{array}{lll}\text { OR } & 95 \% \mathrm{Cl} & p \\ 1.23 & 0.91-1.65 & 0.173 \\ 2.34 & 1.41-3.89 & 0.001 \\ & & \\ 3.41 & 1.94-6.02 & <0.0001 \\ 2.21 & 1.18-4.15 & 0.013 \\ 0.81 & 0.43-1.51 & 0.503\end{array}$

c. Multivariate model 2: Copeptin and laboratory variables ${ }^{a}$

\begin{tabular}{|c|c|c|c|c|c|c|}
\hline \multirow[b]{2}{*}{ Predictors } & \multicolumn{3}{|c|}{ Serious secondary headache** } & \multicolumn{3}{|c|}{ Composite endpoint mortality or hospitalization*** } \\
\hline & OR & $95 \% \mathrm{Cl}$ & $p$ & OR & $95 \% \mathrm{Cl}$ & $p$ \\
\hline Copeptin (In) & 1.80 & $1.33-2.44$ & $<0.0001$ & 1.39 & $1.0-1.94$ & 0.050 \\
\hline Fibrinogen (In) & 1.22 & $0.93-1.61$ & 0.158 & & & \\
\hline Leukocyte count (In) & 1.78 & $0.82-3.83$ & 0.143 & & & \\
\hline C-reactive protein (In) & & & & 1.27 & $1.04-1.56$ & 0.021 \\
\hline
\end{tabular}

${ }^{*} n=75$ events for the primary endpoint, $n=94$ events for the secondary endpoint

${ }^{a}$ All laboratory values were transformed by natural logarithm (In)

${ }^{\mathrm{b}}$ Scenario 4 of Grimaldi et al. [7]: previous headache history presenting with a similar episode

For model 2, we performed a subgroup analysis of ${ }^{* *} n=327$ and ${ }^{* * *} n=279$ patients with available values of fibrinogen, leukocyte count, and C-reactive protein

The greatest potential of copeptin in the studied setting is to rule out serious headache forms by its high negative predictive value with a similar accuracy as the clinical rule based on "red flags". We speculate that the reason lies in the non-specific and prompt elevation of copeptin in stress situations. Besides the underlying disease in secondary headache forms, pain itself as a stress stimulus may have contributed to the increase in copeptin levels. This would explain why some individual patients with migraine also had very high copeptin values. So far, there is only data on copeptin levels in relation to chest pain but not to other pain stimuli. In chest pain, copeptin levels are higher in acute myocardial infarction than in extracardiac chest pain [29]. Thus, if pain stimuli are rather small and other relevant stress stimuli are lacking, low copeptin levels should accurately identify benign headache forms.

\section{Conclusion}

Copeptin was independently associated with serious secondary headache as compared to benign headaches forms. Copeptin may be a promising novel blood biomarker for risk stratification in patients with nontraumatic headache. 


\section{Appendix}

\section{Definition of serious secondary NTH}

A serious NTH will require subsequent treatment of the underlying disease or condition. If untreated, the patient faces the risk of permanent damage or death.

The following diagnoses were selected from the list of secondary NTH in the ICHD-II criteria [9] as meeting the above criterion:

- [G44.81] Headache attributed to cranial or cervical vascular disorder, i.e. the following:

Headache attributed to

- ischaemic stroke or transient ischaemic attack

- non-traumatic intracranial haemorrhage

- unruptured vascular malformation

- vasculitis

- cerebral venous thrombosis (CVT)

- other intracranial vascular disorder

- Headache or facial or neck pain attributed to arterial dissection

- [G44.813] Headache attributed to arterial hypertension, i.e. the following:

Headache attributed to

- phaeochromocytoma

- hypertensive crisis without hypertensive encephalopathy

- hypertensive encephalopathy

- pre-eclampsia

- eclampsia

- other

- [G44.82] Headache attributed to non-vascular intracranial disorder, i.e. the following:

- high cerebrospinal fluid pressure

- idiopathic intracranial hypertension (IIH)

- intracranial hypertension secondary to metabolic, toxic or hormonal causes

- intracranial hypertension secondary to hydrocephalus

- low cerebrospinal fluid pressure

- epileptic seizure

- other non-vascular intracranial disorder

- [G44.82] Headache attributed to non-infectious inflammatory disease, i.e. the following:

Headache attributed to

- neurosarcoidosis

- aseptic (non-infectious) meningitis

- lymphocytic hypophysitis
- other non-infectious inflammatory disease

- [G44.822] Headache attributed to intracranial neoplasm

- [G44.4 or G44.83] Headache attributed to a substance or its withdrawal, i.e. the following:

- Carbon monoxide-induced headache

- Cocaine-induced headache

- Other

- [G44.821] Headache attributed to intracranial infection

- [G44.84] Headache or facial pain attributed to disorder of cranium, neck, eyes, ears, nose, sinuses, teeth, mouth or other facial or cranial structures, i.e. the following:

- Headache attributed to acute glaucoma

- Other

- [G44.847, G44.848 or G44.85] Cranial neuralgias and central causes of facial pain, i.e. the following:

- Optic neuritis

- Head or facial pain attributed to acute herpes zoster

- other

\section{Additional file}

Additional file 1: Spreadsheet of study data. (XLSX $57 \mathrm{~kb}$ )

\section{Abbreviations}

AUC: Area under the curve; $\mathrm{Cl}$ : Confidence interval; ED: Emergency Department; ICHD: International Classification of Headache Disorders; IQR: Interquartile range; ROC: Receiver operating characteristic; VAS: Visual analogue scale

\section{Acknowledgements}

We gratefully thank the staff of the emergency departments of all participating hospitals in supporting this study. Furthermore, we thank the many supporting doctors, nurses, medical students and laboratory personnel at all participating centers, especially Prof. Ulrich W. Buettner, Vreni Wyss, Martha Kaeslin Meyer, Renate Hunziker, Uzma Mirza, and Jasmin Martin.

Funding

MCC, CB, MK: This study was supported by a grant by the Swiss National Foundation (PPOP3 123346) to MCC and to MK (PZ00P3_142422), the Nora van Meeuwen Häfliger Stiftung and the Gottfried Julia Bangerter-Rhyner Stiftung, and a grant to CB from the Vizerektorat of the University Basel. BM, CB and PhS: Research funds from the Department of Endocrinology, Diabetology and Metabolism, the Medical University Clinic, the W\&W Fund of the Kantonsspital Aarau, and the "Argovia Professorship" of the Medical Faculty of the University of Basel.

Availability of data and materials

The dataset supporting the conclusions of this article is included within the article and its Additional file 1. 


\section{Authors' contributions}

$\mathrm{CB}, \mathrm{PhS}, \mathrm{KT}, \mathrm{MA}, \mathrm{BM}, \mathrm{MK}$ and $\mathrm{MCC}$ designed the study and wrote the protocol. PeS, KN and RB made substantial contributions to the protocol design. $C B, B W, N N, K N, B M$, and $M C C$ coordinated the study. CB, NN, BW, RB, $K T, C M, K H, J T, S B, T K$ and $M A$ recruited patients for the study. $C B, N N, B W$, $\mathrm{KT}, \mathrm{KH}, \mathrm{JT}, \mathrm{MK}, \mathrm{MCC}, \mathrm{SB}, \mathrm{PhS}, \mathrm{PeS}, \mathrm{KN}, \mathrm{BM}, \mathrm{HA}$, and $\mathrm{KH}$ participated in data gathering and evaluation. $C B, M K$ and $M C C$ analyzed the data and drafted the manuscript. BW, NN, PhS, SB, TK, CM, KT, KH, JT, MA, HA, RB, PeS, KN, and $\mathrm{BM}$ critically revised the manuscript. All authors read and approved the final manuscript.

\section{Competing interests}

MCC, PhS, MK and BM received speaker honoraria, consultant fees and unrestricted research grant for projects unrelated to this study from Thermofisher AG, the manufacturer of the Copeptin assay. RB has received honoraria for presentations, unrestricted grants for research and for educational purposes from Boehringer-Ingelheim, AstraZeneca, Bayer, and ThermoFisher AG unrelated to this study.

$\mathrm{CB}, \mathrm{BW}, \mathrm{NN}, \mathrm{SB}, \mathrm{TK}, \mathrm{CM}, \mathrm{KT}, \mathrm{KH}, \mathrm{JT}, \mathrm{MA}, \mathrm{AH}, \mathrm{PeS}$, and NK declare no competing interests.

\section{Consent for publication}

Written informed consent was obtained from all participants for publication of anonymized data in this manuscript. The consent forms are held by the authors' institutions and are available for review by the Editor-in-Chief.

\section{Ethics approval and consent to participate}

This trial adheres to the declaration of Helsinki and was registered at clinicaltrials.gov as NCT01174901 on 08/02/2010. The trial results are reported according to the latest version of the STROBE statement [48]. The local ethics committees (Ethikkommission beider Basel EKBB No. 197/10 and Kantonale Ethikkommission KEK AG No. 2011/002) approved the study protocol. All patients gave informed consent before entering the trial.

\section{Author details}

'Division of Endocrinology, Department of Internal Medicine, University Hospital Basel, Basel, Switzerland. ${ }^{2}$ Department of Neurology, Medical University Clinic, Kantonsspital Aarau, Aarau, Switzerland. ${ }^{3}$ Internal Medicine, Medical University Clinic, Kantonsspital Aarau, Tellstrasse, CH-5001 Aarau, Switzerland. ${ }^{4}$ Clinic of Neurology, University Hospital Basel, Basel, Switzerland. ${ }^{5}$ Center of Laboratory Medicine, Kantonsspital Aarau, Aarau, Switzerland. ${ }^{6}$ Emergency Department, University Hospital Basel, Basel, Switzerland. ${ }^{7}$ Neurology, RehaClinic AG, Bad Zurzach, Switzerland. ${ }^{8}$ Clinic of Neurology, University Hospital Zürich, Zürich, Switzerland. ${ }^{9}$ Max-Planck-Institute for Metabolism Research, Cologne, Germany.

Received: 25 November 2016 Accepted: 7 February 2017 Published online: 13 February 2017

\section{References}

1. Schuetz P, Christ-Crain M, Wolbers M, Schild U, Thomann R, Falconnier C, Widmer I, Neidert S, Blum CA, Schonenberger R, Henzen C, Bregenzer T, Hoess C, Krause M, Bucher HC, Zimmerli W, Muller B, Pro Hsg (2007) Procalcitonin guided antibiotic therapy and hospitalization in patients with lower respiratory tract infections: a prospective, multicenter, randomized controlled trial. BMC Health Serv Res 7:102

2. Locker T, Mason S, Rigby A (2004) Headache management-are we doing enough? An observational study of patients presenting with headache to the emergency department. Emerg Med J 21:327-332

3. Morgenstern LB, Huber JC, Luna-Gonzales H, Saldin KR, Grotta JC, Shaw SG, Knudson L, Frankowski RF (2001) Headache in the emergency department. Headache 41:537-541

4. Stevenson RJ, Dutta D, MacWalter RS (1998) The management of acute headache in adults in an acute admissions unit. Scott Med J 43:173-176

5. Ang SH, Chan YC, Mahadevan M (2009) Emergency department headache admissions in an acute care hospital:why do they occur and what can we do about it? Ann Acad Med Singapore 38:1007-1010

6. Ramirez-Lassepas M, Espinosa CE, Cicero JJ, Johnston KL, Cipolle RJ, Barber DL (1997) Predictors of intracranial pathologic findings in patients who seek emergency care because of headache. Arch Neurol 54:1506-1509
7. Grimaldi D, Nonino F, Cevoli S, Vandelli A, D’Amico R, Cortelli P (2009) Risk stratification of non-traumatic headache in the emergency department. J Neurol 256:51-57

8. Cortelli P, Cevoli S, Nonino F, Baronciani D, Magrini N, Re G, De Berti G, Manzoni GC, Querzani P, Vandelli A (2004) Evidence-based diagnosis of nontraumatic headache in the emergency department: a consensus statement on four clinical scenarios. Headache 44:587-595

9. Headache Classification Subcommittee of the International Headache Society (2004) The International Classification of Headache Disorders: 2nd edition. Cephalalgia 24 Suppl 1:9-160

10. Holle D, Obermann M (2013) The role of neuroimaging in the diagnosis of headache disorders. Ther Adv Neurol Disord 6:369-374

11. Locker TE, Thompson C, Rylance J, Mason SM (2006) The utility of clinical features in patients presenting with nontraumatic headache: an investigation of adult patients attending an emergency department. Headache 46:954-961

12. Breen DP, Duncan CW, Pope AE, Gray AJ, Al-Shahi Salman R (2008) Emergency department evaluation of sudden, severe headache. QJM 101:435-443

13. Loder E, Harrington MG, Cutrer M, Sandor P, De Vries B (2006) Selected confirmed, probable, and exploratory migraine biomarkers. Headache 46 : $1108-1127$

14. Kosinski CM, Mull M, Schwarz M, Koch B, Biniek R, Schlafer J, Milkereit E, Willmes K, Schiefer J (2004) Do normal D-dimer levels reliably exclude cerebral sinus thrombosis? Stroke 35:2820-2825

15. Guldiken S, Guldiken B, Demir M, Kabayel L, Ozkan H, Turgut N, Hunkar R, Kat S (2011) Soluble CD40 ligand and prolactin levels in migraine patients during interictal period. J Headache Pain 12:355-360

16. Arulmani U, Maassenvandenbrink A, Villalon CM, Saxena PR (2004) Calcitonin gene-related peptide and its role in migraine pathophysiology. Eur J Pharmacol 500:315-330

17. Meng R, Wang $X$, Hussain M, Dornbos D 3rd, Meng L, Liu Y, Wu Y, Ning M, Ferdinando SB, Lo EH, Ding Y, Ji X (2014) Evaluation of plasma D-dimer plus fibrinogen in predicting acute CVST. Int J Stroke 9:166-173

18. Egea-Guerrero JJ, Revuelto-Rey J, Murillo-Cabezas F, Munoz-Sanchez MA Vilches-Arenas A, Sanchez-Linares P, Dominguez-Roldan JM, Leon-Carrion J (2012) Accuracy of the S100beta protein as a marker of brain damage in traumatic brain injury. Brain Inj 26:76-82

19. Blyth BJ, Farhavar A, Gee C, Hawthorn B, He H, Nayak A, Stocklein V, Bazarian JJ (2009) Validation of serum markers for blood-brain barrier disruption in traumatic brain injury. J Neurotrauma 26:1497-1507

20. Teepker M, Munk K, Mylius V, Haag A, Moller JC, Oertel WH, Schepelmann $K$ (2009) Serum concentrations of s100b and NSE in migraine. Headache 49:245-252

21. Forcelini CM, Dantas DC, Luz C, Santin R, Stein AT, Barros HM, Barea LM (2011) Analysis of leukocytes in medication-overuse headache, chronic migraine, and episodic migraine. Headache 51:1228-1238

22. Durham P, Papapetropoulos S (2013) Biomarkers associated with migraine and their potential role in migraine management. Headache 53:1262-1277

23. Widmer IE, Puder JJ, Konig C, Pargger H, Zerkowski HR, Girard J, Muller B (2005) Cortisol response in relation to the severity of stress and illness. J Clin Endocrinol Metab 90:4579-4586

24. Katan M, Muller B, Christ-Crain M (2008) Copeptin: a new and promising diagnostic and prognostic marker. Crit Care 12:117

25. Katan M, Christ-Crain M (2010) The stress hormone copeptin: a new prognostic biomarker in acute illness. Swiss Med Wkly 140:W13101

26. Friedman BW, Hochberg ML, Esses D, Grosberg B, Corbo J, Toosi B, Meyer RH, Bijur PE, Lipton RB, Gallagher EJ (2007) Applying the International Classification of Headache Disorders to the emergency department: an assessment of reproducibility and the frequency with which a unique diagnosis can be assigned to every acute headache presentation. Ann Emerg Med 49:409-419, 419 e401-409

27. Marlow RA, Kegowicz CL, Starkey KN (2009) Prevalence of depression symptoms in outpatients with a complaint of headache. J Am Board Fam Med 22:633-637

28. Lipton RB, Stewart WF, Sawyer J, Edmeads JG (2001) Clinical utility of an instrument assessing migraine disability: the Migraine Disability Assessment (MIDAS) questionnaire. Headache 41:854-861

29. Reichlin T, Hochholzer W, Stelzig C, Laule K, Freidank H, Morgenthaler NG, Bergmann A, Potocki M, Noveanu M, Breidthardt T, Christ A, Boldanova T, Merki R, Schaub N, Bingisser R, Christ M, Mueller C (2009) Incremental value of copeptin for rapid rule out of acute myocardial infarction. J Am Coll Cardiol 54:60-68 
30. Morgenthaler NG, Struck J, Alonso C, Bergmann A (2006) Assay for the measurement of copeptin, a stable peptide derived from the precursor of vasopressin. Clin Chem 52:112-119

31. Katan M, Fluri F, Morgenthaler NG, Schuetz P, Zweifel C, Bingisser R, Muller K, Meckel S, Gass A, Kappos L, Steck AJ, Engelter ST, Muller B, Christ-Crain M (2009) Copeptin: a novel, independent prognostic marker in patients with ischemic stroke. Ann Neurol 66:799-808

32. Zweifel C, Katan M, Schuetz P, Siegemund M, Morgenthaler NG, Merlo A, Mueller B, Christ-Crain M (2010) Copeptin is associated with mortality and outcome in patients with acute intracerebral hemorrhage. BMC Neurol 10:34

33. Kruger S, Ewig S, Kunde J, Hanschmann A, Marre R, Suttorp N, Welte T (2009) C-terminal provasopressin (copeptin) in patients with community-acquired pneumonia-influence of antibiotic pre-treatment: results from the German competence network CAPNETZ. J Antimicrob Chemother 64:159-162

34. Seligman R, Papassotiriou J, Morgenthaler NG, Meisner M, Teixeira PJ (2008) Copeptin, a novel prognostic biomarker in ventilator-associated pneumonia. Crit Care 12:R11

35. Hanley JA, MCNeil BJ (1982) The meaning and use of the area under a receiver operating characteristic (ROC) curve. Radiology 143:29-36

36. Jensen MB, Chacon MR, Sattin JA, Aleu A, Lyden PD (2008) The promise and potential pitfalls of serum biomarkers for ischemic stroke and transient ischemic attack. Neurologist 14:243-246

37. Vickers AJ, Cronin AM, Begg CB (2011) One statistical test is sufficient for assessing new predictive markers. BMC Med Res Methodol 11:13

38. L'Abate P, Wiegert S, Struck J, Wellmann S, Cannizzaro V (2013) Determinants of plasma copeptin: a systematic investigation in a pediatric mechanical ventilation model. Respir Physiol Neurobiol 185:222-227

39. Morgenthaler NG, Muller B, Struck J, Bergmann A, Redl H, Christ-Crain M (2007) Copeptin, a stable peptide of the arginine vasopressin precursor, is elevated in hemorrhagic and septic shock. Shock 28:219-226

40. Muller B, Morgenthaler N, Stolz D, Schuetz P, Muller C, Bingisser R, Bergmann A, Tamm M, Christ-Crain M (2007) Circulating levels of copeptin, a novel biomarker, in lower respiratory tract infections. Eur J Clin Invest 37:145-152

41. Katan M, Morgenthaler N, Widmer I, Puder JJ, Konig C, Muller B, Christ-Crain M (2008) Copeptin, a stable peptide derived from the vasopressin precursor, correlates with the individual stress level. Neuro Endocrinol Lett 29:341-346

42. Aliberti S, Di Pasquale M, Zanaboni AM, Cosentini R, Brambilla AM, Seghezzi S, Tarsia P, Mantero M, Blasi F (2012) Stratifying risk factors for multidrugresistant pathogens in hospitalized patients coming from the community with pneumonia. Clin Infect Dis 54:470-478

43. Riquelme R, Jimenez P, Videla AJ, Lopez H, Chalmers J, Singanayagam A, Riquelme M, Peyrani P, Wiemken T, Arbo G, Benchetrit G, Rioseco ML, Ayesu K, Klotchko A, Marzoratti L, Raya M, Figueroa S, Saavedra F, Pryluka D, Inzunza C, Torres A, Alvare P, Fernandez P, Barros M, Gomez Y, Contreras C, Rello J, Bordon J, Feldman C, Arnold F, Nakamatsu R, Riquelme J, Blasi F, Aliberti S, Cosentini R, Lopardo G, Gnoni M, Welte T, Saad M, Guardiola J, Ramirez J (2011) Predicting mortality in hospitalized patients with 2009 H1N1 influenza pneumonia. Int J Tuberc Lung Dis 15:542-546

44. Torres A, Blasi F, Peetermans WE, Viegi G, Welte T (2014) The aetiology and antibiotic management of community-acquired pneumonia in adults in Europe: a literature review. Eur J Clin Microbiol Infect Dis 33:1065-1079

45. Buse DC, Loder EW, Gorman JA, Stewart WF, Reed ML, Fanning KM, Serrano D, Lipton RB (2013) Sex differences in the prevalence, symptoms, and associated features of migraine, probable migraine and other severe headache: results of the American Migraine Prevalence and Prevention (AMPP) Study. Headache 53:1278-1299

46. Charles PG, Whitby M, Fuller AJ, Stirling R, Wright AA, Korman TM, Holmes PW, Christiansen K, Waterer GW, Pierce RJ, Mayall BC, Armstrong JG, Catton MG, Nimmo GR, Johnson B, Hooy M, Grayson ML (2008) The etiology of community-acquired pneumonia in Australia: why penicillin plus doxycycline or a macrolide is the most appropriate therapy. Clin Infect Dis 46:1513-1521

47. Ananda-Rajah MR, Charles PG, Melvani S, Burrell LL, Johnson PD, Grayson ML (2008) Comparing the pneumonia severity index with CURB-65 in patients admitted with community acquired pneumonia. Scand J Infect Dis 40:293-300

48. von Elm E, Altman DG, Egger M, Pocock SJ, Gotzsche PC, Vandenbroucke JP (2007) The Strengthening the Reporting of Observational Studies in Epidemiology (STROBE) statement: guidelines for reporting observational studies. PLoS Med 4:e296

\section{Submit your manuscript to a SpringerOpen ${ }^{\circ}$ journal and benefit from:}

- Convenient online submission

- Rigorous peer review

- Immediate publication on acceptance

- Open access: articles freely available online

- High visibility within the field

Retaining the copyright to your article

Submit your next manuscript at $\boldsymbol{s p r i n g e r o p e n . c o m ~}$ 